\title{
HUBUNGAN ASUPAN KALIUM, KALSIUM DAN MAGNESIUM DENGAN KEJADIAN HIPERTENSI PADA WANITA MENOPAUSE DI KELURAHAN BOJONGSALAMAN, SEMARANG
}

\author{
Etika Hasna Dina Putri, Apoina Kartini*) \\ Program Studi Ilmu Gizi Fakultas Kedokteran Universitas Diponegoro \\ Jl.Dr.Sutomo No.18, Semarang, Telp (024) 8453708, Email : gizifk@undip.ac.id
}

\begin{abstract}
Background: Hypertension is one of the degenerative diseases can be found in both men and women. Menopausal women have a higher risk of hypertension. Potassium, calcium, and magnesium intake is assosiated with hypertension.

Objective : To determine correlation between potassium, calcium and magnesium intake with hypertension.

Methodology: This case contro study included 68 menopausal women in Bojongsalaman Semarang and was selected using consecutive sampling method. Data on potassium, calcium, and magnesium intake wareobtained using Semi Quantitative Food Frequency Questionnaire. Data on blood presssure was measures using digital sphygmomanomater. Bivariate analyzed was analyzed using chi square test.

Results: Subjects in the case group had a calcium and less potassium intake are 97,1\%and 91,2\% respectively. Both case and control group had adequate magnesium intake. Results of bivariat analysis showed that was a significant correlation between magnesium intake with hypertension $(p=0,02, O R=4,27,95 \% C l=1,135-16,137)$

Conclusion :Nutrient intake that associated with hypertension in menopausal women was magnesium, whereas calsium and potassium intake in this study failed to prove the correlation with hypertennsion .
\end{abstract}

Keywords: hypertension; potassium; calcium and magnesiumintake

\section{ABSTRAK}

Latar Belakang : Hipertensi merupakan salah satu penyakit degeneratif yang dapat ditemukan baik pada laki-laki maupun perempuan. Wanita menopause lebih beresiko terhadap kejadian hipertensi. Asupan kalium, kalsium dan magnesium berhubungan dengan terjadinya hipertensi.

Tujuan : Mengetahui hubungan asupan kalium, kalsium dan magnesium dengan kejadian hipertensi

Metode : Penelitian case control ini bersubjek 68 wanita menopause di Kelurahan Bojongsalaman yang diperoleh dengan metode consecutive sampling. Asupan kalium, kalsium dan magnesium diperoleh melalui Food Frequency Questionairesemi kuantitatif. Data tekanan darah didapatkan dengan menggunakan sphygmomanometer digital. Analisis data bivariat menggunakan uji chi square

Hasil : Subyek pada kelompok kasus yang memiliki asupan kalsium dan kalium kurang masing - masing sebesar 97,1\% dan 91,2\%. Kelompok kasus maupun kontrol memiliki asupan magnesium yang cukup. Hasil analisis bivariat menunjukkan hubungan yang signifikan antara asupan magnesium dengan kejadian hipertensipada wanita menopause. $(p=0,02, O R=4,27,95 \% C l=1,135-16,137)$

Simpulan: Asupan zat gizi yang berhubungan dengan kejadian hipertensi pada wanita menopause adalah magnesium. Sedangkan asupan kalsium dan kalium dalam penelitian ini tidak berhasil membuktikan adanya hubungan dengan kejadian hipertensi

Kata Kunci : hipertensi; asupan kalium; kalsium; magnesium

\section{PENDAHULUAN}

Hipertensi merupakan salah satu masalah kesehatan masyarakat yang banyak di Indonesia. Hipertensi banyak mengganggu kesehatan masyarakat, banyak orang tidakmenyadari bahwa dirinya menderita hipertensi, hal ini disebabkan gejalanya yang tidak nyata dan pada stadium awal belum menimbulkan gangguan yang serius pada kesehatannya.

Hipertensi diperkirakan menjadi penyebab kematian sekitar 7,1 juta orang di seluruhdunia, yaitu sekitar 13\% dari total kematian. Diperkirakan sekitar $80 \%$ kenaikan kasus hipertensi terutama di negara berkembang tahun 2025 dari sejumlah 639 juta kasus di tahun 2005, diperkirakan menjadi 1,15 milyar kasus ditahun 2025. Prediksi ini didasarkan pada angka penderita hipertensi saat ini dan pertambahan penduduk saat ini. ${ }^{1}$

Sekitar 95\% hipertensi di Indonesia merupakan hipertensi essensial yang tidak diketahui penyebabnya dan bersifat multifaktorial. ${ }^{2}$ Hipertensi essensial biasanya muncul pada pasien yang berusia 25 sampai 55 tahun sedangkan usia di bawah 20 jarang ditemukan. ${ }^{3}$ Kejadian hipertensi meningkat dengan nyata terutama pada wanita setelah usia 45 tahun ke atas karena masa

\footnotetext{
${ }^{*}$ Penulis Penanggungjawab
} 
menopause. ${ }^{4}$ Kejadian hipertensi pada wanita menopause cenderung menyamai bahkan lebih tinggi dari pria karena efek protektif hormon estrogen yang menurun. Wanita menopause menderita hipertensi lebih dari dua kali dibandingkan dengan wanita premenopause. ${ }^{5}$

Beberapa faktor dapat mempengaruhi terjadinya hipertensi, sebagian tidak dapat dihindari seperti bertambahnya usia dan jenis kelamin, tetapi sebagian dapat dicegah seperti kekurangan asupan magnesium, kalsium dan kalium. ${ }^{6,7}$

Kandungan kalium dapat menurunkan tekanan darah dengan mengurangi kandungan natrium dalam urine dan air dengan cara yang sama seperti diuretik. Penelitian epidemiologi menunjukkan bahwa asupan rendah Kalium akan mengakibatkan peningkatan tekanan darah.Diet tinggi kalium yang terdapat pada sayur dan buah juga dapat menurunkan resiko kardiovaskuler dengan menghambat trombosis arterial, aterosklerosis, dan hipertrofi medial pada dinding arteri. $^{7,8}$

Mikronutrien yang berperan dominan dalam patogenesis hipertensi essensial adalah kalsium dan magnesium. Penelitian tahun 2002 yang dimuat dalam American Journal Clinical Nutrition menyatakan bahwa efek penurunan kadar magnesium di dalam tubuh terjadi pada wanita yang telah mengalami menopause. ${ }^{9}$ Magnesium merupakan salah satu nutrien paling penting untuk kesehatan jantung. Tugas utama magnesium adalah membantu otot jantung untuk relaksasi. Fungsi ini berlawanan dengan fungsi mineral kalsium yang membuat jantung berkontraksi.Menurut US Departement of Health and Human Service, hipomagnesemia sering ditemukan pada penderita tekanan darah tinggi. ${ }^{10}$

Kadar kalsium di dalam darah penting karena kalsium juga memiliki peranan penting dalam pengaturan tekanan darah dengan cara membantu kontraksi otot-otot pada dinding pembuluh darah serta memberi sinyal untuk pelepasan hormon-hormon yang berperan dalam pengaturan tekanan darah. ${ }^{7,8,11}$

Kerja duet dari magnesium dan kalsium inilah yang berguna untuk mempertahankan irama jantung tetap normal dengan relaksasi dan kontraksi otot jantung.Asupan Magnesium dan kalsium dapat juga berpengaruh terhadap tekanan darah, namun pengaruhnya akan terlihat jika digabung antara asupan magnesium dan kalsium. ${ }^{7}$ Begitu juga yang direkomendasikan oleh DASH (Dietary Approaches to Stop Hypertension), diet kaya magnesium, kalsium merupakan komponen yang efektif untuk menurunkan tekanan darah selama 2 minggu dengan komposisi $500 \mathrm{mg}$ magnesium dan $1250 \mathrm{mg}$ kalsium. Konsumsi kalsium rata-rata masyarakat Indonesia yaitu sebesar $254 \mathrm{mg} /$ hari atau hanya seperempat dari standar internasional, yaitu sebesar 1000-1200 $\mathrm{mg} /$ hari untuk orang dewasa. ${ }^{12}$

Berdasarkan Profil Kesehatan Jawa Tengah terdapat $554.771(67,57 \%)$ kasus penyakit hipertensi pada tahun 2012. ${ }^{13}$ Data dari Dinas Kesehatan Kota Semarang menunjukkanprevalensi kasus hipertensi sebesar 49,1\% ditahun 2012 dengan jumlah kasus paling banyak pada kelompok usia 45-65 dan angka kejadian terbesar pada wanita. Menurut hasil survey Dinas Kesehatan Kota Semarang pada tahun 2012, salah satu kejadian hipertensi essensial tertinggi di Kota Semarang terjadi di Puskesmas Karangayu yaitu sebesar 1280 kasus. ${ }^{14}$

Berdasarkan uraian tersebut peneliti berminat meneliti hubungan asupan magnesium, kalsium dan kalium dengan kejadian hipertensi pada wanita menopause di Kelurahan Bojongsalaman, Kecamatan Karangayu.

\section{METODE PENELITIAN}

Penelitian ini dilaksanakan di Kelurahan Bojongsalaman, Semarang pada bulan Mei - Juni 2014 dengan disiplin ilmu yang terkait adalah gizi masyarakat. Penelitian ini merupakan penelitian observasional dengan menggunakan desain case control tanpa matching sehingga dapat diketahui beberapa faktor risiko dari beberapa zat gizi yang mempunyai pengaruh terhadap kejadian hipertensi.

Populasi dalam penelitian ini adalah wanita menopause di Kelurahan Bojongsalaman. Jumlah subyek dalam penelitian ini adalah 34 wanita menopause hipertensi dan 34 wanita menopause normotensi dipilih dengan metode consecutive sampling. Kriteria inklusi adalah wanita menopause usia 46 - 60 tahun dimana usia $46-55$ tahun termasuk kategori lansia awal dan $\geq$ 56 tahun merupakan lansia akhir, tidak mengkonsumsi obat penurun tekanan darah, bertempat tinggal di kelurahan Bojongsalaman, bersedia mengisi formulir penelitian inform consent, untuk kelompok kontrol memiliki tekanan darah normal (sistolik 110-120 $\mathrm{mmHg}$ dan atau diastolik 70-80 $\mathrm{mmHg}$ ) dan kelompok kasus memiliki tekanan darah hipertensi (sistolik $\geq 140$ $\mathrm{mmHg}$ dan atau diastolik $\geq 90 \mathrm{mmHg}$ ).

Variabel bebas penelitian terdiri dari asupan kalium, kalsium dan magnesium sedangkan variabel terikatnya adalah hipertensi. Tahap pertama penelitian dilakukan wawancara data 
identitas subyek yaitu meliputi nama, usia, pendidikan, pekerjaan, alamat, dan riwayat hipertensi.Data riwayat hipertensi dalam keluarga dikategorikan menjadi dua yaitu ada, bila salah satu atau kedua orangtua menderita hipertensi dan tidak ada bila kedua orangtua tidak menderita hipertensi. Kemudian dilakukan pengukuran tekanan darah diukur oleh perawat dengan menggunakan sphygmomanometer air raksa sebanyak 2 kali pengukuran kemudian hasilnya di rata-rata. Sebelum dilakukan pengukuran, responden diistirahatkan selama kurang lebih 5 menit dalam posisi duduk pada kursi dengan sandaran. ${ }^{15}$

Tahap selanjutnya dilakukan pengukuran antropometri, meliputi penimbangan berat badan dengan menggunakan timbangan digital (ketelitian $0,1 \mathrm{~kg}$ ) dan pengukuran tinggi badan dengan menggunakan mikrotoa (ketelitian $0,1 \mathrm{~cm}$ ) kemudian diolah guna mendapatkan status gizi subyek berdasarkan Indeks Massa Tubuh (IMT). Dikategorikan obesitas bila $>25 \mathrm{~kg} / \mathrm{m}^{2}$ dan tidak obesitas bila $\leq 25 \mathrm{~kg} / \mathrm{m}^{2}{ }^{16}$ Data aktifitas fisik diperoleh melalui kuesioner International Physical Activity Questionnare (IPAQ), dinyatakan dalam satuan MET.menit/minggu dan dikelompokkan menjadi 2 kategori yaitu rendah jika $<600$
MET.menit/minggudan normal jika > 600 MET.menit/minggu. ${ }^{17}$

Asupan kalium, kalsium, magnesium diperoleh dari 1 kali wawancara kepada subjek dengan menggunakan kuisioner semi quantitative food frequency untuk asupan 1 bulan terakhir. Data yang diperoleh dalam ukuran rumah tangga kemudian dikonversikan ke dalam satuan miligram selanjutnya dianalisis dengan menggunakan software nutrisurvey. Asupan kalium, kalsium, magnesium dikategorikan menjadi dua yaitu cukup dan kurang berdasarkan kebutuhan minimal perhari yaitu $80 \%$ dari total kebutuhan kalium, kalsium dan magnesium. ${ }^{18}$

Pengolahan data dan analisis dilakukan dengan menggunakan program Statistical Package for Social Science (SPSS) 16 for Windows. Analisis univariat dilakukan dengan memasukan data dalam Tabel distribusi frekuensi untuk mendeskripsikan karakteristik subjek. Analisis bivariat menggunakan Uji Chi Square untuk mengetahui hubungan antara variabel dan untuk mengetahui besar resiko variabel independenterhadap variabel dependen.

\section{HASIL PENELITIAN \\ Karakteristik Subjek}

Tabel 1. Karakteristik Subjek, nilai rerata, standar deviasi, nilai minimal dan maksimal menurut usia, pendidikan terakhir, pekerjaan, riwayat hipertensi, aktifitas fisik, indeks massa tubuh

\begin{tabular}{|c|c|c|c|c|c|}
\hline \multirow[t]{2}{*}{ Variabel } & \multicolumn{2}{|c|}{ Kasus $(n=34)$} & \multicolumn{2}{|c|}{ Kontrol $(n=34)$} & \multirow[t]{2}{*}{$\mathbf{P} * *$} \\
\hline & $\mathbf{N}$ & $\%$ & n & $\%$ & \\
\hline Usia & & & & & 0,22 \\
\hline 46-55 tahun & 13 & 38,2 & 18 & 53 & \\
\hline$\geq 56$ tahun & 21 & 61,8 & 16 & 47 & \\
\hline mean $\pm \mathrm{SD}(\min -\max )$ & $55,79 \pm 4,11$ & $(46-50)$ & $55,18 \pm 4,50$ & $(46-60)$ & \\
\hline Pendidikan & & & & & 0,45 \\
\hline Pendidikan Dasar & 19 & 55,9 & 22 & 64,7 & \\
\hline Pendidikan Lanjut & 15 & 44,1 & 12 & 35,3 & \\
\hline Pekerjaan & & & & & 0,40 \\
\hline Bekerja & 7 & 20,6 & 24 & 70,6 & \\
\hline Tidak Bekerja & 27 & 79,4 & 10 & 29,4 & \\
\hline Riwayat Hipertensi & & & & & 0,58 \\
\hline $\mathrm{Ya}$ & 10 & 29,4 & 8 & 23,5 & \\
\hline Tidak & 24 & 70,6 & 26 & 76,5 & \\
\hline Aktifitas Fisik & & & & & 0,77 \\
\hline Kurang & 8 & 23,5 & 7 & 20,6 & \\
\hline Cukup & 26 & 76,5 & 27 & 79,4 & \\
\hline mean $\pm \mathrm{SD}(\min -\max )$ & $989,39 \pm 491,59$ & $(411-3306)$ & $1090 \pm 635,2$ & $(466,5-3346)$ & \\
\hline IMT* & & & & & 0,08 \\
\hline Obesitas & 22 & 64,7 & 15 & 44,1 & \\
\hline Tidak Obesitas & 12 & 35,3 & 19 & 55,9 & \\
\hline mean $\pm \mathrm{SD}(\min -\max )$ & $26,76 \pm 5,03$ & $(18,6-41,3)$ & $24,34 \pm 2,98$ & $(18,9-30)$ & \\
\hline
\end{tabular}

Berdasarkan skrining tekanan darah yang dilakukan terhadap 236 wanita usia 46 - 60 tahun, ditemukan 63 responden $(26,7 \%)$ yang hipertensi. Pada kelompok kasuslebih banyak wanita 
menopause usia $\geq 56$ tahun dengan persentase $61,8 \%$, sedangkan pada kelompok kontrol wanita menopause lebih banyak berusia sekitar 46 - 55 tahun dengan persentase 53\%.Persentase indeks massa tubuh pada kedua kelompok juga berbeda, dalam penelitian ini ditemukan wanita obesitas lebih banyak ditemukan pada kelompok kasus $(64,7 \%)$ dibandingkan kelompok kontrol $(44,1 \%)$. Sedangkan persentase tingkat pendidikan terakhir yang ditempuh wanita pada kelompok kontrol $(64,7 \%)$ dan kelompok kasus $(55,9 \%)$ adalah lulus pendidikan dasar.Hasil penelitian menunjukan bahwa subyek baik kelompok kontrol $(76,5 \%)$ maupun kelompok kasus $(70,6 \%)$ tidak memiliki riwayat hipertensi dalam keluarganya. Persentase aktifitas fisik pada kelompok kasus (76,5\%) maupun kelompok kontrol (79,4\%) termasuk dalam kategori cukup. Data karakteristik subyek dapat dilihat pada Tabel 1.

Tabel 1 menunjukkan bahwa uji beda antara usia, pendidikan, pekerjaan, riwayat hipertensi, aktifitas fisik dan indeks massa tubuh didapatkan nilai $\mathrm{p}>0,05$ yang artinya tidak ada beda antara kelompok kasus maupun kelompok kontrol.

Tabel 2. Nilai rerata, median, standar deviasi, minimum dan maksimum asupan kalium, kalsium, magnesium dan tekanan darah

\begin{tabular}{|c|c|c|c|c|c|c|}
\hline \multirow[t]{2}{*}{ Variabel } & \multicolumn{3}{|c|}{ Kasus } & \multicolumn{3}{|c|}{ Kontrol } \\
\hline & Mean \pm SD & Min & Maks & Mean \pm SD & Min & Maks \\
\hline $\begin{array}{c}\text { Tekanan Darah } \\
\text { Sistolik }\end{array}$ & $141,91 \pm 10,373$ & 120 & 155 & $115,44 \pm 4,150$ & 110 & 120 \\
\hline $\begin{array}{c}\text { Tekanan Darah } \\
\text { Diastolik }\end{array}$ & $90 \pm 3,482$ & 80 & 95 & $73,82 \pm 4,093$ & 70 & 80 \\
\hline $\begin{array}{l}\text { Asupan Kalium } \\
\text { (mg) }\end{array}$ & $2359 \pm 10,373$ & 1376,2 & 4319,7 & $2234 \pm 6766,7$ & 1241,1 & 4051,1 \\
\hline $\begin{array}{c}\text { Asupan } \\
\text { Kalsium (mg) }\end{array}$ & $535,303 \pm 1902,9$ & 244 & 980 & $484,118 \pm 1692,1$ & 255 & 896 \\
\hline $\begin{array}{c}\text { Asupan } \\
\text { Magnesium } \\
\text { (mg) }\end{array}$ & $\begin{array}{c}273,697 \pm \\
42,5122\end{array}$ & 195,7 & 344,8 & $\begin{array}{c}343,538 \pm \\
70,1712\end{array}$ & 200,7 & 546,3 \\
\hline
\end{tabular}

Rata-rata tekanan darah sistolik, tekanan darah diastolik, asupan kalium, asupan kalsium,indeks massa tubuh wanita hipertensi lebih tinggi dibandingkan wanita yang tidak hipertensi.
Sedangkan rerata asupan magnesium dan aktifitas fisik wanita hipertensi lebih rendah dibandingkan wanita tidak hipertensi.

Tabel 3. Hasil uji statistik besar resiko asupan kalium, kalsium, magnesium

\begin{tabular}{|c|c|c|c|c|c|c|c|}
\hline \multirow[t]{2}{*}{ Variabel } & \multicolumn{2}{|c|}{$\begin{array}{l}\text { Kasus } \\
(\mathbf{n}=34)\end{array}$} & \multicolumn{2}{|c|}{$\begin{array}{c}\text { Kontrol } \\
(\mathrm{n}=34)\end{array}$} & \multirow[t]{2}{*}{ OR } & \multirow[t]{2}{*}{ Cl 95\% } & \multirow[t]{2}{*}{$\mathbf{P}$} \\
\hline & $\mathbf{N}$ & $\%$ & $\mathrm{n}$ & $\%$ & & & \\
\hline $\begin{array}{l}\text { Asupan Kalium } \\
\text { Kurang } \\
\text { Cukup }\end{array}$ & $\begin{array}{c}33 \\
1\end{array}$ & $\begin{array}{c}97,1 \\
2,9\end{array}$ & $\begin{array}{c}33 \\
1\end{array}$ & $\begin{array}{c}97,1 \\
2,9\end{array}$ & 1,000 & $0,060-16,668$ & 1,000 \\
\hline $\begin{array}{l}\text { Asupan Kalsium } \\
\text { Kurang } \\
\text { Cukup }\end{array}$ & $\begin{array}{c}31 \\
3\end{array}$ & $\begin{array}{c}91,2 \\
8,8\end{array}$ & $\begin{array}{c}32 \\
2\end{array}$ & $\begin{array}{c}94,1 \\
5,9\end{array}$ & 0,646 & $0,101-4,133$ & 1,000 \\
\hline $\begin{array}{l}\text { Asupan Magnesium } \\
\text { Kurang } \\
\text { Cukup }\end{array}$ & $\begin{array}{l}12 \\
22\end{array}$ & $\begin{array}{l}35,3 \\
64,7\end{array}$ & $\begin{array}{c}4 \\
22\end{array}$ & $\begin{array}{l}11,8 \\
88,2\end{array}$ & 4,091 & $1,162-14,397$ & 0,022 \\
\hline
\end{tabular}

Sebanyak $97,1 \%$ wanita hipertensi maupun wanita normotensi memiliki asupan kalium $<80 \%$ dari total kebutuhan kalium.Tidak ada hubungan yang bermakna antara asupan kalium dengan kejadian hipertensi $(\mathrm{p}=1,000, \mathrm{OR}=1,000,95 \%$ $\mathrm{Cl}=0,060-16,668)$. Asupan kalsium pada kelompok kasus maupun kelompok kontrol sebagian besar masih $<80 \%$ dari total kebutuhan kalsium. Tidak ada hubungan asupan kalsium dengan kejadian hipertensi ( $\mathrm{p}=1,000, \mathrm{OR}=0,646$, $95 \% \mathrm{Cl}=0,101-4,133)$. Subyek baik pada kelompok kasus $(64,7 \%)$ maupun kelompok kontrol $(88,2 \%)$ asupan magnesiumnya $\geq 80 \%$ dari total kebutuhan magnesium. Besar resiko asupan 
magnesium terhadap kejadian hipertensi adalah $4,091 \quad(95 \% \mathrm{Cl}=1,162-14,397)$. Hal ini menunjukkan bahwa terdapat hubungan antara asupan magnesium dengan kejadian hipertensi $(\mathrm{p}=$ 0,022). (Tabel 3)

\section{PEMBAHASAN}

Di Kelurahan Bojongsalamandari 236 wanita menopause didapatkan 63 wanita hipertensi dengan angka prevalensi hipertensi sebesar $26,7 \%$. Prevalensi tersebut lebih rendah dibandingkan prevalensi hipertensi berdasarkan data dari Dinas Kesehatan Kota Semarang. Data dari Dinas Kesehatan Kota Semarang menunjukkan prevalensi kasus hipertensi sebesar 49,1\% ditahun 2012 dengan jumlah kasus paling banyak pada pada kelompok usia 45-65 dan angka kejadian terbesar pada wanita. ${ }^{19}$ Dari data diketahui wanita hipertensi juga lebih banyak terjadi pada wanita usia $\geq 56$ tahun $(61,8 \%)$, seiring dengan pertambahan usia kejadian hipertensi cenderung meningkat karena adanya perubahan fisiologis. ${ }^{20}$ Dan dari perhitungan BMI menunjukkan bahwa sebanyak $64,7 \%$ wanita hipertensi mengalami obesitas, dengan peningkatan berat badan ideal maka resiko hipertensi juga akan meningkat. ${ }^{21}$ Kejadian hipertensi dapat dipengaruhi oleh beberapa faktor salah satunya adalah asupan gizi. Dalam penelitian ini asupan gizi yang diteliti adalah asupan kalium, kalsium dan magnesium.

Hasil penelitian ini menunjukkan bahwa sebagian besar subjek, baik kelompok kasus $(97,1 \%)$ maupun kontrol $(97,1 \%)$ memiliki asupan kalium yang rendah yaitu $<80 \%$ dari total kebutuhan kalium seperti yang ditunjukkanpada Tabel 3. Berdasarkan hasil wawancara semi quantitative food frequency diketahui bahwa sebagian besar subyek kurang mengkonsumsi buah - buahan segar yang merupakan sumber makanan tinggi kalium. Penelitian ini tidak berhasil membuktikanhubungan antara asupan kalium dengan kejadian hipertensi $(p=1,000)$. Namun secara teoritis asupan rendah kalium akan mengakibatkan peningkatan tekanan darah. ${ }^{22,23}$ Kalium dan natrium adalah pasangan mineral yang bekerja sama dalam memelihara keseimbangan cairan, elektrolit, dan asam basa sehingga dua mineral tersebut berpengaruh terhadap regulasi tekanan darah. ${ }^{24}$ Kalium banyak terdapat dalam bahan makanan mentah atau segar. Proses pemasakan makanan dapat menyebabkan hilangnya kalium dalam bahan makanan dan penambahan garam ke dalam proses pemasakan makanan dapat menyebabkan kandungan natrium dalam makanan tersebut semakin meningkat sehingga dapat terjadi perubahan keseimbangan rasio natrium dan kalium dalam makanan tersebut. Pengaruh kalium terhadap tekanan darah terjadi jika natrium di dalam tubuh juga tinggi, tetapi jika asupan natrium normal ataupun kurang maka pengaruh tersebut tidak akan terlihat. Rasio natrium kalium pada urin mempunyai hubungan yang lebih kuat dengan tekanan darah dibandingkan dengan natrium atau kalium sendiri. Penelitian ini tidak berhasil menemukan hubungan asupan kalium dengan kejadian hipertensi kemungkinan dikaitkan penelitian ini hanya melihat asupan kalium saja tanpa melihat rasio natrium kalium di dalam urin. ${ }^{25}$

Hasil penelitian menunjukkan bahwa subyek pada kelompok kasus (91,2\%) maupun kelompok kontrol $(94,1 \%)$ memiliki asupan kalsium yang kurang dan hasil analisis bivariat menunjukkan penelitian ini tidak berhasil membuktikan adanya hubungan antara asupan kalsium dengan kejadian hipertensi $(\mathrm{p}=1,000)$. Namun secara teoritis, kekurangan kalsium akan melemahkan kemampuan otot jantung untuk memompa darah. Hal ini akan berpengaruh terhadap tekanan darah. Jika asupan kalsium kurang dari kebutuhan tubuh maka untuk menjaga keseimbangan kalsium di dalam darah, hormon paratiroid menstimulasi pengeluaran kalsium dari tulang dan masuk ke darah. Kalsium dalam darah akan mengikat asam lemak bebas sehingga pembuluh darah menjadi menebal dan mengeras sehingga dapat mengurangi elastisitas jantung yang akan meningkatkan tekanan darah. ${ }^{26}$ Penelitian ini tidak berhasil menemukan hubungan asupan kalsium dengan kejadian hipertensi mungkin dikaitkan dengan faktor lain seperti halnya faktor genetik individu yang bervariasi. Faktor genetik setiap individu juga mempengaruhi kemampuan tubuh menggunakan kalsium secara optimal untuk menurunkan tekanan darah dan adanya faktor faktor yang menghambat absorbsi kalsium di usus halus seperti fosfor, oksalat dan serat yang masing - masing banyak terdapat dalam makanan berprotein tinggi, sayuran hijau, dan buah - buahan segar sehingga dapat menjadi penyebab tidak optimalnya fungsi kalsium dalam menurunkan tekanan darah. . $^{11,27}$

Pada penelitian ini diketahui bahwa pada kelompok kasus $(64,7 \%)$ maupun kelompok kontrol $(88,2 \%)$ yang memiliki asupan magnesium cukup. Hasil analisis bivariat menunjukkan bahwa terdapat hubungan antara magnesium dengan kejadian hipertensi $(\mathrm{p}=0,022)$. Pengaruh asupan magnesium dengan kejadian hipertensi disebabkan 
terjadinya kontraklititas dan berkurangnya relaksasi pembuluh darah sebagai respon terhadap unsur neurohormonal seperti prostagladin dan amina beta adregenik. ${ }^{28,29}$ Efek magnesium terhadap tekanan darah sangat berperan terhadap pencegahan penyakit kardiovaskuler. ${ }^{24}$ Magnesium mempunyai peranan penting dalam upaya pengontrolan tekanan darah dengan memperkuat jaringan endotel, menstimulasi prostagladin dan meningkatkan penangkapan glukosa sehingga resistensi insulin dapat terkurangi. Selain itu, magnesium juga berperan dalam kontraksi otot jantung. Bila konsentrasi magnesium dalam darah menurun maka otot jantung tidak dapat bekerja secara maksimal sehingga mempengaruhi tekanan darah. $^{7,20}$ Kurang optimalnya fungsi asupan magnesium yang berasal dari makanan dalam menurunkan tekanan darah dapat disebabkan oleh serat, oksalat, fitat dan fosfor yang dapat menghambat absorbsi magnesium di dalam usus halus. Selain itu, faktor stres mental dan fisik juga cenderung menurunkan absorbsi magnesium dan meningkatkan eksresinya. ${ }^{24}$

\section{SIMPULAN}

Angka prevalensi hipertensi wanita menopause di Kelurahan Bojongsalaman sebesar 26,7\%. Penelitian ini membuktikanadanya hubungan antara asupan magnesium dengan kejadian hipertensi. Namun, dalam penelitian ini tidak berhasil membuktikan adanya hubungan asupan kalium dan kalsium dengan kejadian hipertensi pada wanita menopause.

\section{SARAN}

Perlu diadakan penyuluhan terhadap masyarakat khususnya wanita menopause mengenai pentingnya mengkonsumsi kalium, kalsium dan magnesium yang cukup untuk mencegah kejadian hipertensi melalui kegiatan

\section{DAFTAR PUSTAKA}

1. American Heart Association. Internacional Cardiovascular Disease Statistic [internet]. 2004 [cited 2011 Oct 8]. Available from: http://americanheart.org/

2. Yogiantoro, Mohammad. 2006. Hipertensi Esensial. Dalam : Buku Ajar Ilmu PenyakitDalam Jilid I Edisi IV. FKUI, Jakarta

3. Massie BM. Hipertensi sistemik. Dalam : Tierney LM, McPhee SJ, Papadakis MA. Diagnosisi dan terapi ilmu kedokteran ilmu penyakit dalam: Jakarta: Salemba Medika; 2002. Hal 382-410

4. Boedhi Darmojo. Pola konsumsi makan da penyakit kardiovaskuler. Medika: 1999; 24(1): 335
5. Debra AK. Medical nutrition therapy in cardiovascular disease. In: Mahan LK, Escott Stump S, Editors. Krause's food nutrition and diet therapy. 11th Ed. USA: Saunders; 2004. p. 860-91.

6. US Departement of Health and Human Service. 2006. Your Guide to Lowering Your Blood Pressure with DASH: DASH Eating Plan. USA: NIH Publication

7. Krummel, D.A., 2008. Medical Nutrition Therapy for Cardiovascular Disease. In: Mahan, L.K., Escott-Stump, S., Krausse's Food and Nutirition Therapy. Canada: Saunders Elsvier, 834- 835.

8. McCullough MJ, Savage NW. Oral candidosis and the therapeutic use of antifungalagents in dentistry. Aust Dent J 2005;50(2):S36-9.

9. Joffres MR, Reed DM, Yano K. Relationship of magnesium intake and other dietary factors to blood pressure : The Honolulu Heart Study. Am J Clin Nurt [ serial online] 2010; 45:469-75. Available from : URL :http://www.ajcn.org

10. Selly Nurhelyanti. Hubungan kegemukan, asupan natrium , kalsium, kalium dengan kejadian hipertensi pada wanita. [skripsi]. Semarang: Fakultas Kedokteran UniversitasDiponegoro; 2008

11. McCarron DA, Morris CD, Young E, Roullet C and Drueke T. Dietary calcium and blood pressure modifying factors in spesific population. Am Jclinn Nurt [ serial online] 2010; 54:215S-19S. Available from : URL :http://www.ajcn.org

12. Frank M, et.al, 2001. Effect On Blood Pressure of Reduced Dietary Sodium and Dietary Approach to Stop Hypertension (DASH) Diet. http://www.nejm.org Vol : 344(1):3-10.

13. Kepala Dinas Kesehatan Provinsi Jawa Tengah. Profil Kesehatan Jawa Tengah. Semarang : Dinas Kesehatan Provinsi Jawa Tengah. 2012.

14. Dinas Kesehatan kota Semarang. Rekap Prevalensi PTM Kota Semarang Tahun 2012. Semarang, 2012.

15. British Hypertension Society. Guidelines for management of hypertension: Report of the Fourth Working Party for the British Hypertension Society. J Hum Hypertension. 2004;18:139-85

16. Sugondo S. Obesitas. Dalam : Buku Ajar Ilmu Penyakit Dalam Jilid III Edisi IV. Jakarta: FK UI;2006. Hal 1922

17. International Physical Activity Questionnare. Guidelines for data processing and analysis of the International Physical Activity Questionnare (IPAQ). Short and long form. Revised November 2005. Available from : $\underline{w w w . i p a q . k i . s e}$

18. Widajanti Laksmi, 2009. Survei Konsumsi Gizi. BP UNDIP Semarang.

19. Dinas Kesehatan kota Semarang. Rekap Prevalensi PTM Kota Semarang Tahun 2012. Semarang, 2012.

20. Kotchen TA. Nutrition, diet and Hypertension. In : Shils ME, Shike M, Ross AC, Caballero B, Cousins RJ, editors. Modern nutrition in health and 
Disease. 10th Edition. Philadelpia. Lippincott Williams and Wilkins; 2006. P.1095-1107

21. Sugiharto, Aris, Lylyasari, Riyadi, Muniroh, Wirjatmadi, dkk. 2007.

22. McCullough M, Lin PH. Nutrition, diet, and hypertension. In: Coulston AM, Rock CL, Monsen ER, editors. Nutrition in the prevention and treatment of disease. San Diego:Academic Press; 2001.p. 303-1

23. Theodore AK, Jane Morley K. Nutrition, Diet and Hypertension. Modern Nutrition in Health and Disease. Tenth edition. Philadelphia: Lippincott Williams and Wilkins; 2006.p. 1095-1102

24. Rolfes SR, Pinna K, Whitney E. Water and the major mineral. In: Understanding normal and clinical nutrition. 7th edition. USA: Thomson wadsworth; 2006. P. 411-22

25. Appel LJ, Brands MW, Sacks FM, Karanja N, Elmer PJ, Daniels SR. Dietary approaches to prevent and treat hypertension. Hypertension [serial online] 2006 [dikutip 18 maret 2009]; 47: [13 layar] . Available from: URL:http://www.hypertension.org

26. Jorde R, Bonaa KH. Calcium from dairy product, vitamin $\mathrm{D}$ intake, and blood presssure: the Tromso study. Am J Clin Nurt [ serial online] 2000; 71:1530-5. Available from : URL :http://www.ajcn.org

27. Lu W, Manson JE, Buring JE, I-Min L, Sesso HD. Dietary Intake of Diary product, calcium and vitamin $\mathrm{D}$ and the risk hypertension in middleaged and older woman. Hypertension: Journal of The American Heart Association [ serial online] 2008; 51:1073-79. Availabel from : URL :http://www.hypertensionaha.org

28. Zhao L, Stamler J, Lijing L, Zhao YB, Wu Y, Liu $\mathrm{K}$, et al. Blood pressure diffrences between northen and southtern chinese. Hypertension: Journal Of The American Heart Association [serial online] 2004 [dikutip 6 Juni 2010]; 15:183-89. Available from:.

URL:http://www.hypertensionaha.org

29. Budiman. Peranan gizi pada pencegahan dan penanggulangan hipertensi. Medika Desember 1999;25 (12): 784-8 